Functional

Ecology 2003

17, 555-561

\title{
How feather colour reflects its carotenoid content
}

\author{
LAURI SAKS* + KEVIN McGRAW $\dagger$ and PEETER HÕRAK* \\ *Institute of Zoology and Hydrobiology, Tartu University, Vanemuise 46, 51014 Tartu, Estonia, $\dagger$ Department of \\ Neurobiology and Behavior, Cornell University, Ithaca, NY 14853, USA
}

\begin{abstract}
Summary
1. Many birds sequester carotenoid pigments in colourful patches of feathers to advertise or compete for mates. Because carotenoids can be scarce in nature and serve valuable physiological functions, only the highest-quality individuals are thought to acquire or allocate more pigments for use in sexual displays.
\end{abstract}

2. A critical but rarely tested assumption of carotenoid-based signals is that the colour of pigmented feather patches directly reveals the total amount of carotenoids contained within them.

3. We studied the relationship between carotenoid-based coloration (hue, chroma and brightness) and the pigment content of tail feathers in wild-caught and captive male greenfinches (Carduelis chloris [Linnaeus]). Greenfinches incorporate two main carotenoids - canary xanthophylls A and B - into feathers to develop yellow patches of colour in their tail.

4. Variation in feather carotenoid content explained $32-51 \%$ of variation in chroma and hue of the yellow parts of tail feathers, while feather brightness was not significantly related to carotenoid concentration. Hence, chroma and hue appear good candidates to indicate feather carotenoid content.

5. Birds with the most colourful feathers deposited significantly more of both canary xanthophylls into plumage. Thus, there does not appear to be a specific biochemical strategy for becoming colourful in greenfinches; males instead follow the general decision rule to deposit as many xanthophylls as possible into feathers to become yellow.

Key-words: Canary xanthophyll, Carduelis chloris, feather carotenoid content, plumage coloration

Functional Ecology (2003) 17, 555-561

\section{Introduction}

During past decades, carotenoid pigments have received increased attention in the study of sexual selection. Carotenoids are common components of the colourful red, orange and yellow sexual ornaments in animals (Goodwin 1984). These molecules also play an important role as free-radical scavengers, protecting the nervous system from oxidative damage and stimulating immune defence (Bendich 1989; Lozano 1994; Olson \& Owens 1998; Møller et al. 2000). Because they must be acquired from the diet (Fox 1979) and are destroyed when used as antioxidants (Vershinin 1999), it is believed that carotenoids are limited for use as colorants in feathers, skin and scales. Therefore carotenoids have been suggested to play a major role in the mechanisms of sexual selection, because individuals may face a trade-off between allocation of carotenoids to colour signals and the use of carotenoids for other
$\$$ Author to whom the correspondence should be addressed. Fax: +372 7375 830. E-mail: slauris@ut.ee vital activities (reviews in Lozano 1994; Olson \& Owens 1998; Møller et al. 2000). Only the highest-quality individuals can accumulate sufficient quantities of pigments to develop the most colourful signals.

The idea that carotenoid-based signals might reflect an individual's quality is supported by several correlational and experimental studies that link the colour of carotenoid-containing patches to foraging efficiency (Hill, Inouye \& Montgomerie 2002; Senar \& Escobar 2002), disease status (reviewed in Lozano 1994; Hill 1999; McGraw \& Hill 2000) and immunocompetence (reviewed in Møller et al. 2000). However, a key, underlying assumption in all of this work is that the colour of carotenoid-based ornaments accurately reflects the amount of carotenoids that are contained within the pigment patch. Recent advances in analytical biochemistry now allow for reliable identification of the carotenoid pigments present in bird feathers (Hudon \& Brush 1992; Stradi, Celentano \& Nava 1995a). Because pigmented feathers typically contain several different carotenoids that can vary in colour from yellow to orange to red (Stradi 1998), it is conceivable 
556

L. Saks,

K. McGraw

\& P. Hõrak
(C) 2003 British Ecological Society, Functional Ecology, 17, 555-561 that there are very subtle, underlying biochemical mechanisms that control colour expression and that may be important for understanding the costs and signal content of these sexual traits (McGraw et al. 2002).

To our knowledge, the relationship between plumage coloration (scored by comparison to colour plates) and carotenoid content has been assessed in a single study by Inouye et al. (2001) in house finches (Carpodacus mexicanus). However, colour cannot be objectively measured by the human eye and the vision of birds is different from that of humans (e.g. Endler 1990, but see Hill 1998 for comparison of visually and spectrophotometrically acquired colour measurements). Therefore, to understand how feather colour truly relates to its carotenoid content, studies relying on spectrophotometric measurements of plumage colour are needed.

Thus, the aim of the current study is to elucidate whether and how spectrophotometrically measured colour parameters reflect feather carotenoid content. For this purpose, we measured the colour of the yellow part of tail feathers in male greenfinches (Carduelis chloris [Linnaeus]) and subsequently determined the types and amounts of carotenoid pigments contained within them. Previous work has shown that the carotenoid-based yellow ornamental feathers of male greenfinches contain two yellow carotenoids - canary xanthophylls A and B - as major pigments (Stradi et al. 1995b; Stradi 1998). These carotenoid-containing colour patches serve as sexually selected traits (Eley 1991), indicating an individual's ability to resist parasite infections and overall health and immunocompetence (Merilä, Sheldon \& Lindström 1999; Lindström \& Lundström 2000; Saks, Ots \& Hõrak 2003). Following previous studies (e.g. Endler 1990; Hill 1998; Grill \& Rush 2000), we used three commonly used components of colour (hue, chroma and brightness) to characterise plumage-colour variation in this species.

\section{Materials and methods}

A total of 29 male greenfinches were caught in mistnets in the Vaibla bird station in Central Estonia $\left(58^{\circ} 24^{\prime} \mathrm{N} ; 26^{\circ} 3^{\prime} \mathrm{E}\right)$ between 2 and 20 October 2001. Birds were transported to Tartu and housed in individual indoor cages $(27 \times 51 \times 55 \mathrm{~cm})$. The study was carried out from 18 January to 6 March 2002 . The birds were fed ad libitum with sunflower seeds and tap water. During the study period, birds were held on the natural day-length cycle. The study was conducted under licence from the Estonian Ministry of the Environment and all the birds were released back into their natural environment after the experiment.

\section{STUDY SPECIES}

Greenfinches are medium-sized (c. $28 \mathrm{~g}$ ) gregarious seed-eating passerines native to the western Palearctic region (Cramp \& Perrins 1994). Males are larger and more colourful (Svensson 1992; Merilä et al. 1999) with yellow, carotenoid-based (Stradi et al. 1995b) markings on the sides of the tail feathers, primaries, primary covers and breast. Females are smaller and lacking full yellow tints in their plumage (Cramp \& Perrins 1994).

\section{RESEARCH PROTOCOL}

On 18 January the right, outermost, sixth tail feather of each individual was collected (hereafter wild-grown feathers). This particular feather was chosen because it is the most visibly exposed one and probably contains information that is representative of the whole colour signal. In the three individuals where the feather on the right side of the tail was missing, the feather sample was taken from the left side of the tail. The feather that grew to replace the collected wild-grown feather was plucked on 6 March (hereafter lab-grown feathers). During the growth of replacement feathers half of the birds were cured from coccidiosis using Vetacox PLV (Sanofy-Synthelabo Inc., Paris, France) treatment, while another half was infected with Isospora lacazei (the results of this experiment will be reported elsewhere).

\section{ANALYSES}

\section{Feather coloration}

Collected feathers were placed into a plastic bag and stored in the dark until measurements were carried out. Colour was measured in an area of the visible carotenoid-pigmented surface of the feather of approximately $1 \mathrm{~mm}^{2}$ using a spectrophotometer (Ocean Optics S2000, Dunedin, FL, USA). The measurements were taken from the standard position from the dorsal side of the feather on both vanes, $c$. $5 \mathrm{~mm}$ inward (away, towards the body from the apex of the feather) from the end of the black-coloured tip area of the feather (Fig. 1). Measurements were taken twice from both inner and outer vane of the feather and the resulting four measurements were averaged as to obtain total feather coloration estimates. Light from a halogen light source (Ocean Optics LS-1) was transferred to the feather through a quartz optic fibre (Ocean Optics), reaching the feather at $90^{\circ}$. The sampling optic was placed at $45^{\circ}$ to the surface of the sample and connected to a spectrophotometer by a quartz fibre optic cable. Data from the spectrophotometer were digitalized by a DAQ Card 700 and passed into a computer with appropriate software (OOIBase). The measurements were relative and referred to a standard white reference tile (WS-2) and to the dark. Each measurement provided a measure of reflectance for each 1-nm interval in the range of 400-700 $\mathrm{nm}$. To estimate colour, we calculated values of hue, chroma and brightness (see Endler 1990 for details). Hue can be understood as the everyday meaning for colour (yellow, green, red, etc.). Hue is a correlate of the shape of the reflectance 
557

Feather colour and carotenoid content

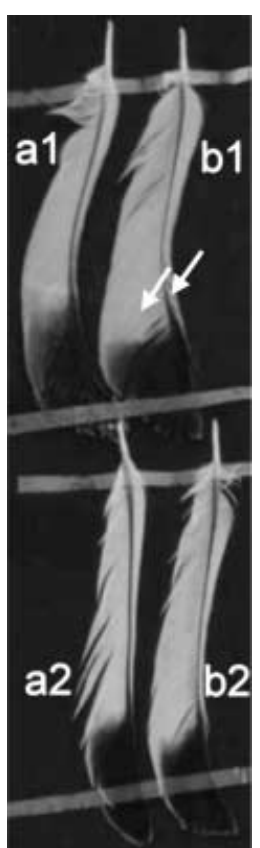

\begin{tabular}{|c|c|c|c|c|c|}
\hline & Sample & Hue & Chroma & Brightness & $\begin{array}{l}\text { Carotenoid } \\
\text { content }\end{array}$ \\
\hline Wild-grown & a1 & $58 \cdot 3$ & $0 \cdot 24$ & 18619 & $502 \cdot 5$ \\
\hline feathers & b1 & $63 \cdot 1$ & $0 \cdot 28$ & 16827 & $548 \cdot 2$ \\
\hline Lab-grown & $\mathrm{a} 2$ & $54 \cdot 9$ & $0 \cdot 18$ & 12021 & $45 \cdot 7$ \\
\hline feathers & b2 & $56 \cdot 9$ & $0 \cdot 13$ & 28792 & $18 \cdot 3$ \\
\hline
\end{tabular}

Fig. 1. Tail feathers of male greenfinches: their colour measurements and carotenoid content $\left(\mu \mathrm{g} \mathrm{g}^{-1}\right)$. Arrows indicate the approximate position of taking colour measurements.

spectrum, measured in degrees, around a circular spectrum (colour wheel) whereas chroma is a measure of the 'purity' or 'saturation' of a colour. Brightness may be defined as the total amount (intensity) of light reflected from the measured surface. Hue and chroma were calculated as follows:

$$
\begin{array}{ll}
\text { Hue }=\arctan \left\{\frac{[(\mathrm{Qy}-\mathrm{Qb}) / \mathrm{Qt}]}{[(\mathrm{Qr}-\mathrm{Qg}) / \mathrm{Qt}]}\right\} & \text { eqn 1 } \\
\text { Chroma }=\sqrt{(\mathrm{Qr}-\mathrm{Qg})^{2}+(\mathrm{Qy}-\mathrm{Qb})^{2}} & \text { eqn 2 }
\end{array}
$$

In both equations, Qr denotes the summed reflectance in the red area of the reflectance spectrum (between $625 \mathrm{~nm}$ and $700 \mathrm{~nm}$ ), Qg is summed reflectance in green area of the spectrum (between $475 \mathrm{~nm}$ and $550 \mathrm{~nm})$, Qy is summed reflectance in the yellow area of the spectrum (between $550 \mathrm{~nm}$ and $625 \mathrm{~nm}$ ), Qb is summed reflectance in the blue area of the spectrum (between $400 \mathrm{~nm}$ and $475 \mathrm{~nm}$ ) and Qt (brightness) is summed reflectance between $400 \mathrm{~nm}$ and $700 \mathrm{~nm}$. The repeatabilities of colour measurements were calculated using the data from the measured feathers of all birds according to Lessells \& Boag (1987) and are presented in Appendix 1.

\section{Feather carotenoid content}

The yellow-pigmented portions of the sampled feathers were trimmed off and weighed to the nearest $0.01 \mathrm{mg}$ with an electronic balance (Mettler Toledo AG245, Greifensee, Switzerland). The carotenoids were extracted from feathers using acidified pyridine (Hudon \& Brush 1992; McGraw et al. 2002). Feather

(C) 2003 British Ecological Society, Functional Ecology, 17, 555-561 portions were placed into separate $9-\mathrm{mL}$ glass tubes containing $3 \mathrm{~mL}$ acidified pyridine, capped under nitrogen, and held at $95^{\circ} \mathrm{C}$ for $4 \mathrm{~h}$. After cooling to room temperature, $3 \mathrm{~mL}$ of distilled $\mathrm{H}_{2} \mathrm{O}$ was added to the tube and vortexed. Then $3 \mathrm{~mL}$ of hexane was added and shaken for $2 \mathrm{~min}$. The suspension was then centrifuged for $10 \mathrm{~min}$ at 2500 r.p.m. The supernatant hexane phase, containing the carotenoids, was transferred to a fresh glass tube and evaporated to dryness under a stream of nitrogen. This residue was resuspended by adding $200 \mu \mathrm{L}$ of HPLC mobile phase (46: $46: 8$, acetonitrile : methanol : chloroform, v/v/v) to each tube.

$50 \mu \mathrm{L}$ of each sample was injected into a Waters ${ }^{\mathrm{TM}}$ 717plus Autosampler HPLC (Millipore Corp., Milford, MA, USA) fitted with a Develosil RPAqueous C-30 column $(250 \times 4.6$ I.D.) (Nomura Chemical Co. Ltd, Japan). The column was held at a constant temperature of $26^{\circ} \mathrm{C}$ using a column heater. An isocratic system (HP 1050 Series Isocratic Pump), using the aforementioned mobile phase for $22 \mathrm{~min}$, was used for the analysis at a constant flow rate of $0.6 \mathrm{~mL} \mathrm{~min}^{-1}$ (column pressure c. $1000 \mathrm{psi}$ ). We determined the identity of pigments by comparing their retention times to those of authentic reference carotenoids provided by R. Stradi. Pigments eluted on the column as follows: canary xanthophyll B (13.4 min), canary xanthophyll A (13.9 min), cis isomers of canary xanthophyll A (15 and $15.5 \mathrm{~min}$ ) and cis isomers of canary xanthophyll $\mathrm{B}$ (19.6 and 20.4 $\mathrm{min}$ ). The total carotenoid concentration $\left(\mu \mathrm{g} \mathrm{g}^{-1}\right)$ in each sample was determined by absorbance spectrophotometry (Bausch and Lomb Spectronic 1001, Rochester, NY, USA). The carotenoid content in feathers was calculated by following formula:

$\underset{\text { Content }}{\text { Total carotenoid }}=\frac{\mathrm{A} \times \text { volume of extract }(\mathrm{mL})}{\mathrm{E} \times \text { feather mass }(\mathrm{g})}$ eqn 3

where $A$ is the absorbance of the sample $\left(\lambda_{\max }=440\right.$ for xanthophylls) and $\mathrm{E}$ is the extinction $1 \%$ per $1 \mathrm{~cm}$ of 
L. Saks,

K. McGraw

\& P. Hõrak

Table 1. The average concentrations ( $\mu \mathrm{g} \mathrm{g}^{-1}$ feather $\pm \mathrm{SD}$ ) of carotenoids deposited and average percentage of total carotenoids deposited into the feathers of greenfinches $(n=25)$

\begin{tabular}{lccccc}
\hline & \multicolumn{2}{l}{ Wild-grown feathers } & & \multicolumn{2}{l}{ Laboratory-grown feathers } \\
\cline { 2 - 3 } & Concentration & Percentage* & & Concentration & Percentage* \\
\hline Canary xanthophyll B & $258 \cdot 5 \pm 87 \cdot 5$ & $59 \cdot 1$ & & $23 \cdot 4 \pm 12 \cdot 98$ & $78 \cdot 5$ \\
Canary xanthophyll A & $92 \cdot 1 \pm 32 \cdot 1$ & $21 \cdot 1$ & & $6 \cdot 4 \pm 4 \cdot 02$ & $21 \cdot 5$ \\
cis Canary xanthophyll B & $13 \cdot 1 \pm 6 \cdot 85$ & $3 \cdot 0$ & & & \\
cis Canary xanthophyll A & $73 \cdot 8 \pm 26 \cdot 1$ & $16 \cdot 9$ & & \\
\hline
\end{tabular}

* Percentage of total carotenoid content.

the relevant carotenoids at $\lambda_{\max }(3120$ for xanthophylls; Britton 1985).

\section{Results}

Carotenoids deposited into the wild-grown tail feathers of male greenfinches consisted of canary xanthophyll $\mathrm{B}(\mathrm{CXB})$, canary xanthophyll A (CXB), and their cis isomers (cisCXB and cisCXA). In lab-grown feathers, only the presence of CXB and CXA was detected. The concentrations and proportions of carotenoids deposited into feathers are given in Table 1. Concentrations of individual carotenoids were highly intercorrelated between one another $(r=0 \cdot 77-0.97 ; n=25$; all $P<$ $0 \cdot 00001)$. Thus, birds who deposit more of one type of pigment in feathers deposit more of the three other carotenoid pigments.

Chroma of both lab- and wild-grown feathers was positively correlated with the total carotenoid content of the feathers. Among the lab-grown feathers, hue increased with increasing feather carotenoid content, while no such relationship emerged among wild grown-feathers. No significant relationships between feather carotenoid content and feather brightness could be detected (all relationships depicted in Fig. 2).

Wild-grown feathers were more colourful than labgrown feathers (Fig. 1). Average values of chroma and hue were, respectively, $48 \%$ and $8 \%$ higher than those of lab-grown feathers (both $P<0.00001$; paired $t$-test), while the brightness of lab- and wild-grown feathers did not differ $(P=0 \cdot 8)$. Wild-grown feathers had nearly 15 times higher average total carotenoid concentration $\left(437.5 \mu \mathrm{g} \mathrm{g}^{-1} \pm 29.96\right.$ (SE)) than lab-grown feathers $\left(29.8 \mu \mathrm{g} \mathrm{g}^{-1} \pm 3.38(\mathrm{SE}) ; t=13.75 ; P<0.0001\right.$; $n=25)$.

\section{Discussion}

Greenfinch feathers with higher values of chroma and hue had higher total carotenoid content. To our knowledge, this study presents the first direct evidence that spectrophotometric measurements of plumage coloration can be used to estimate the amount of carotenoids deposited in bird feathers. This finding is important for numerous studies testing associations between carotenoid-based plumage coloration and estimates of individual quality such as vigour, health and infection status (reviews in Lozano 1994; Olson \& Owens 1998; Møller et al. 2000).

These relationships between feather colour and carotenoid content hold for a particularly wide data range in the case of chroma, where feather colour correlated with its carotenoid content among both pale labgrown feathers and also among the conspicuous plumes grown under natural conditions (Fig. 2). Plumage hue, on the other hand, reflected its carotenoid content only among lab-grown feathers, which contained nearly 15 times less carotenoids than wildgrown feathers. This suggests that the degree to which different colour parameters reflect feather carotenoid content is not necessarily similar or even linear within the range of observable variation.

It should be noted that the proportion of variance in plumage colour explained by feather carotenoid content $(32-51 \%)$ was not particularly high, indicating that a considerable amount of variation in plumage colour could be ascribed to other potential factors. This is not perhaps surprising, given that plumage colour is not based only upon the pigments but also on feather structure (e.g. Auber 1957; Fox \& Vevers 1960; Vevers 1982). Feather structure, in turn has been shown to be very sensitive to developmental stress and abrasion. Feather coloration may therefore indicate individual qualities complementary or different from those conveyed by the carotenoid pigments within (reviewed by Fitzpatrick 1998). This notion is reinforced by the lack of correlation between total feather brightness and carotenoid content. The brightness is measured as the summed reflectance between $400 \mathrm{~nm}$ and $700 \mathrm{~nm}$ (Endler 1990), so a completely white surface should give the maximum brightness measurements. Further, one might expect that abraded or worn feathers are less glossy and therefore reflect less light, completely independent of their carotenoid content (Fitzpatrick 1998). On the other hand, brightness measurements may be correlated to the reflectance measurements of narrower segments of the spectrum (yellow, red, etc.) reflecting pigment-specific tones. For example, in the case of breast plumage of male greenfinches, reflectance in the yellow band of the spectrum was highly $(r=0.97)$ correlated with total brightness (L. Saks et al. unpublished data). In the same data set,
Ecological Society, Functional Ecology, 17, 555-561 

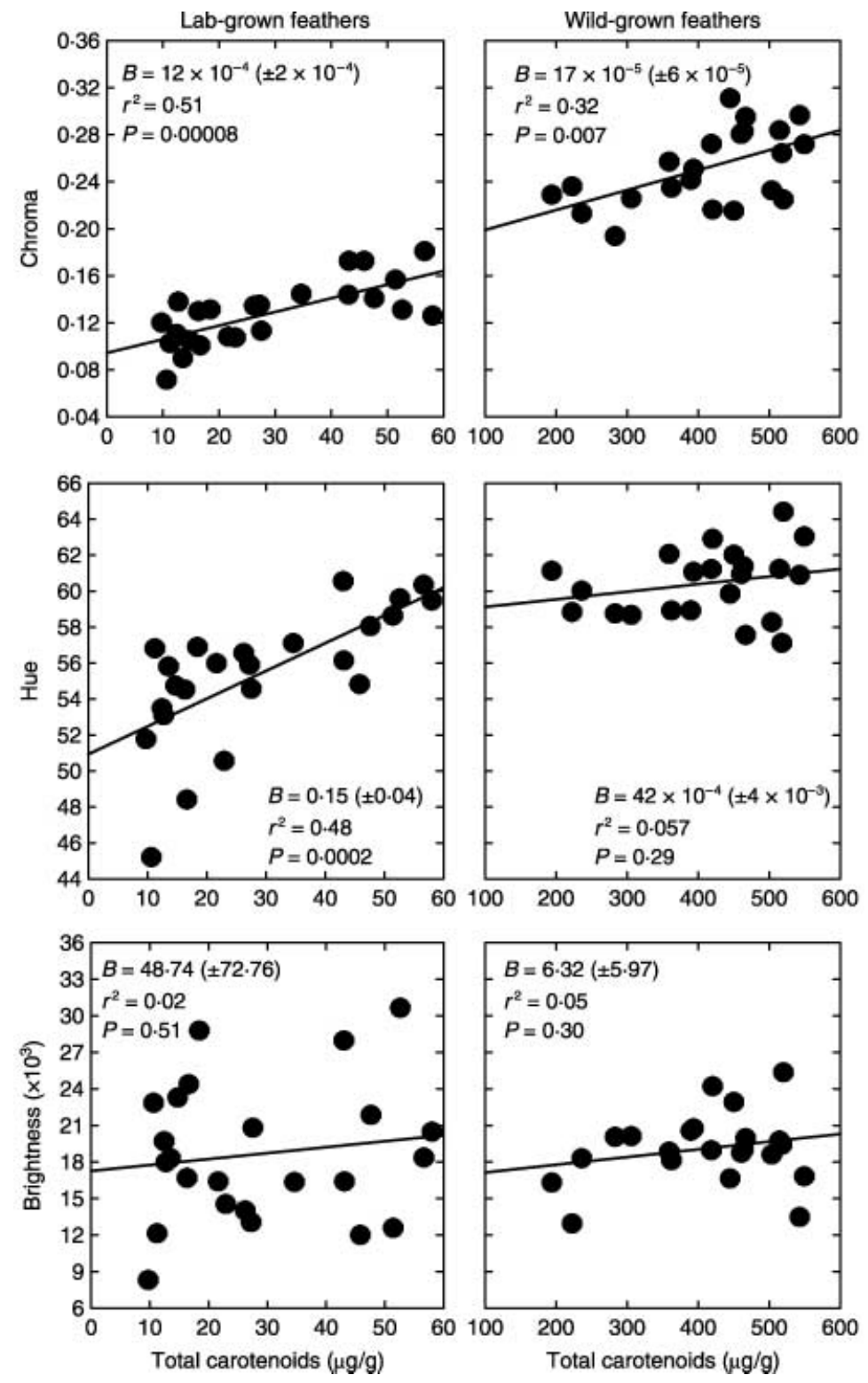

Fig. 2. Relationships between total carotenoid content and colour measurements of the feathers (slope \pm SE).

Saks et al. (2003) found that higher yellow reflectance of breast feathers was associated with better general health state and immunocompetence. Colour intensity of yellow feather ornaments was also shown to predict leukocyte haemoconcentrations in the study of cirl buntings (Emberiza cirlus) by Figuerola et al. (1999). Therefore, brightness measurements should not be totally discarded in the analysis of relationships between colour signals and individual phenotypic quality.

Finally, we cannot exclude the possibility that the slight discordance between the area of the feather from which the coloration and carotenoid content were measured might have obscured the correlations between feather colour and carotenoid content. This could occur because colour measurements were averaged for two $c .1 \mathrm{~mm}^{2}$ patches, while carotenoid concentrations were obtained from the total yellowcoloured feather area (Fig. 1). Further loss of the explanatory power of models could possibly be ascribed to the measurement error of colour variables (note the relatively low repeatabilities of some colour parameters in Appendix 1).

Determining individual pigment types in feathers allowed us to investigate the relative pigmenting roles of different plumage carotenoids. In the only other study linking carotenoid content to feather colour, Inouye et al. (2001) studied the remarkable variation in plumage coloration of house finches, ranging from red to orange to yellow, and found 13 different pigments in colourful feathers that varied equally as much in colour (from red ketocarotenoids to yellow hydroxycarotenoids). Pigment types were often inversely correlated within individual feathers, as certain carotenoids were favoured (e.g. 3-hydroxy-echninenone) or avoided (e.g. lutein) to acquire the most sexually attractive red plumage colour. This suggests that house finches follow a very complex and specific biochemical strategy for becoming colourful, and provides an interesting
Ecological Society, Functional Ecology, 17, 555-561 
contrast with the greenfinches studied here. Greenfinch feathers vary more subtly in colour (bright to dull yellow) and contain a rather simple profile of two yellow canary xanthophylls (Stradi et al. 1995b; this study). Concentrations of the component xanthophylls were highly intercorrelated within greenfinch feathers; birds with more colourful feathers contained more of all types of carotenoids. This indicates that, quite different from house finches, greenfinches follow a very simple strategy of depositing all available yellow pigments into feathers. Canary xanthophylls are quite similar in structure (and thus colour) and are manufactured from similar hydroxycarotenoid substrates (lutein and zeaxanthin) in the diet (Stradi 1998; McGraw et al. 2002), so there may be little need to accumulate preferentially one xanthophyll over the other to acquire the brightest coloration.

In conclusion, we have found that the canary xanthophyll content of greenfinch tail feathers can be estimated by spectrophotometric measurements of hue and chroma. However, the question whether or not the same colour parameters also relate to feather carotenoid content in species where the main feather carotenoid is lutein (e.g. great tit, Parus major, Slagsvold \& Lifjeld 1985) or some other suite of carotenoids (e.g. common crossbill, Loxia curvirostra, Stradi et al. 1996; and linnet Carduelis cannabina, Stradi et al. 1997) requires further investigation.

\section{Acknowledgements}

We thank Indrek Ots, Ulvi Karu, Lea Tegelmann and Helen Vellau for assistance in taking care of birds and data collection. Two anonymous referees provided constructive criticism on the manuscript. The study was financially supported by Estonian Science Foundation grant no. 4537 (to P.H.) and the United States Environmental Protection Agency (Graduate STAR Fellowship no. 91584201-0 to K.J.M.).

\section{References}

Auber, L. (1957) The distribution of structural colours and unusual pigments in the class Aves. Ibis 99, 463-467.

Bendich, A. (1989) Carotenoids and the immune response. Journal of Nutrition 119, 112-115.

Britton, G. (1985) General carotenoid methods. Methods in Enzymology 111, 113-149.

Cramp, P. \& Perrins, C.M. (1994) The Birds of the Western Palearctic, Vol. VII. Oxford University Press, Oxford.

Eley, C. (1991) Status signalling in the Western greenfinch (Carduelis chloris). PhD Thesis, University of Sussex, UK.

Endler, J.A. (1990) On the measurement and classification of colour in studies of animal colour patterns. Biological Journal of the Linnean Society 41, 315-352.

Figuerola, J., Munoz, E., Gutierrez, R. \& Ferrer, D. (1999) Blood parasites, leucocytes and plumage brightness in the

(C) 2003 British Ecological Society, Functional Ecology, 17, 555-561
Cirl bunting, Emberiza cirlus. Functional Ecology 13, 594 601.

Fitzpatrick, S. (1998) Colour schemes for birds: structural coloration and signals of quality in feathers. Annales Zoologici Fennici 35, 67-77.
Fox, D.L. (1979) Biochromy. University of California Press, Berkeley, USA.

Fox, H.M. \& Vevers, G. (1960) The Nature of Animal Colours. Macmillan, New York.

Goodwin, T.W. (1984) The Biochemistry of the Carotenoids, Vol. II. Animals. Chapman \& Hall, London.

Grill, C.P. \& Rush, V.N. (2000) Analysing spectral data: comparison and application of two techniques. Biological Journal of the Linnean Society 69, 121-138.

Hill, G.E. (1998) An easy, inexpensive means to quantify plumage coloration. Journal of Field Ornithology 69, 353-363.

Hill, G.E. (1999) Mate choice, male quality, and carotenoidbased plumage coloration. Proceedings of the International Ornithological Congress 22 (eds N. Adams \& R. Slotow), pp. 1654-1668. University of Natal, Durban.

Hill, G.E., Inouye, C.Y. \& Montgomerie, R. (2002) Dietary carotenoids predict plumage coloration in wild house finches. Proceedings of the Royal Society of London B $\mathbf{6 9}$, 1119-1124.

Hudon, J. \& Brush, A.H. (1992) Identification of carotenoid pigments in birds. Methods in Enzymology 213, 312-321.

Inouye, C.Y., Hill, G.E., Stradi, R.D. \& Montgomerie, R. (2001) Carotenoid pigments in male House Finch plumage in relation to age, subspecies, and ornamental coloration. Auk 118, 900-915.

Lessells, C.M. \& Boag, P.T. (1987) Unrepeatable repeatabilities: a common mistake. Auk 104, 116-121.

Lindström, K. \& Lundström, J. (2000) Male Greenfinches (Carduelis chloris) with brighter ornaments have higher virus infection clearance rate. Behavioral Ecology and Sociobiology 48, 44-51.

Lozano, G.A. (1994) Carotenoids, parasites, and sexual selection. Oikos 70, 309-311.

McGraw, K.J. \& Hill, G.E. (2000) Differential effects of endoparasites on the expression of carotenoid- and melanin-based ornamental coloration. Proceedings of the Royal Society of London B 267, 1525-1531.

McGraw, K.J., Hill, G.E., Stradi, R. \& Parker, R.S. (2002) The effect of dietary carotenoid access on sexual dichromatism and plumage pigment composition in the American Goldfinch. Comparative Biochemistry and Physiology B 131, 261-269.

Merilä, J., Sheldon, B.C. \& Lindström, K. (1999) Plumage brightness in relation to haematozoan infections in the Greenfinch Carduelis chloris: bright males are a good bet. Ecoscience 6, 12-18.

Møller, A.P., Biard, C., Blount, J.D., Houston, D.C., Ninni, P., Saino, N. \& Surai, P.F. (2000) Carotenoid-dependent signals: indicators of foraging efficiency, immunocompetence or detoxification ability? Avian and Poultry Science Reviews 11, 137-159.

Olson, V. \& Owens, I.P.F. (1998) Costly sexual signals: are carotenoids rare, risky or required. Trends in Ecology and Evolution 13, 510-514.

Saks, L., Ots, I. \& Hõrak, P. (2003) Carotenoid-based plumage coloration of male Greenfinches reflects health and immunocompetence. Oecologia 134, 301-307.

Senar, J.C. \& Escobar, D. (2002) Carotenoid-derived plumage coloration in the siskin Carduelis spinus is related to foraging ability. Avian Science 2, 19-24.

Slagsvold, T. \& Lifjeld, J.T. (1985) Variation in plumage color of the great tit Parus major in relation to habitat season and food. Journal of Zoology 206, 321-328.

Stradi, R. (1998) The Colour of Flight. Solei Gruppo Editoriale Informatico, Milan.

Stradi, R., Celentano, G., Boles, M. \& Mercato, F. (1997) Carotenoids in bird plumage: the pattern in a series of redpigmented Carduelinae. Comparative Biochemistry and Physiology B 117, 85-91.

Stradi, R., Celentano, G. \& Nava, D. (1995a) Separation and identification of carotenoids in bird's plumage by 


\section{1}

Feather colour and carotenoid content high-performance liquid chromatography-diode-array detection. Journal of Chromatography B 670, 337-348.

Stradi, R., Celentano, G., Rossi, E., Rovati, G. \& Pastore, M. (1995b) Carotenoids in bird plumage - I. The carotenoid pattern in a series of Palearctic Carduelinae. Comparative Biochemistry and Physiology B 110, 131-143.

Stradi, R., Rossi, E., Celentano, G. \& Bellardi, B. (1996) Carotenoids in bird plumage: the pattern in three Loxia species and in Pinicola enucleator. Comparative Biochemistry and Physiology B 113, 427-432.
Svensson, L. (1992) Identification Guide to European Passerines. L. Svensson, Stockholm.

Vershinin, A. (1999) Biological functions of carotenoids diversity and evolution. Biofactors 10, 99-104.

Vevers, G. (1982) The Colours of Animals. Studies in Biology Series No. 146. Edward Arnold, London.

Received 16 January 2003; revised 7 April 2003; accepted 29 April 2003

\section{Appendix 1}

The repeatabilities of the feather colour measurements

\begin{tabular}{|c|c|c|c|c|c|c|}
\hline & \multicolumn{3}{|c|}{ Wild-grown feathers } & \multicolumn{3}{|c|}{ Laboratory-grown feathers } \\
\hline & $r$ & $P_{\text {one-sided }}$ & $F$ & $r$ & $P_{\text {one-sided }}$ & $F$ \\
\hline \multicolumn{7}{|l|}{ Inner vane } \\
\hline Hue & $0 \cdot 69$ & $0 \cdot 00001$ & $5 \cdot 50_{26,27}$ & $0 \cdot 59$ & $0 \cdot 0003$ & $3 \cdot 84_{25 ; 26}$ \\
\hline Chroma & $0 \cdot 73$ & $<0.00001$ & $6 \cdot 50_{26 ; 27}^{2,27}$ & $0 \cdot 86$ & $<0 \cdot 00001$ & $13 \cdot 34_{25 ; 26}$ \\
\hline Brightness & 0.79 & $<0.00001$ & $8 \cdot 56_{26 ; 27}$ & $0 \cdot 95$ & $<0 \cdot 00001$ & $35 \cdot 68_{25 ; 26}$ \\
\hline \multicolumn{7}{|l|}{ Outer vane } \\
\hline Hue & $0 \cdot 79$ & $<0.00001$ & $8 \cdot 50_{28 ; 29}$ & $0 \cdot 50$ & $0 \cdot 0019$ & $3 \cdot 03_{24 ; 25}$ \\
\hline Chroma & $0 \cdot 81$ & $<0.00001$ & $9 \cdot 79_{28 ; 29}$ & $0 \cdot 88$ & $<0.00001$ & $15 \cdot 17_{24 ; 25}$ \\
\hline Brightness & $0 \cdot 90$ & $<0.00001$ & $18 \cdot 35_{28 ; 29}$ & $0 \cdot 89$ & $<0 \cdot 00001$ & $16 \cdot 92_{24,25}$ \\
\hline
\end{tabular}

